\title{
Role of Free Radicals and Poly(ADP-ribose) Synthetase in Intestinal Tight Junction Permeability
}

\author{
Salvatore Cuzzocrea, ${ }^{1}$ Emanuela Mazzon, ${ }^{2}$ Angela De Sarro, ${ }^{1}$ \\ and Achille P. Caputi ${ }^{1}$ \\ ${ }^{1}$ Institute of Pharmacology, University of Messina, Italy \\ ${ }^{2}$ Department of Biomorphology, School of Medicine, University of Messina, Italy \\ Accepted May 23, 2000.
}

\begin{abstract}
Background: Small intestine permeability is frequently altered in inflammatory bowel disease and may be caused by the translocation of intestinal toxins through leaky small intestine tight junctions (TJ) and adherence $(1,2)$. The role of hydrogen peroxide $\left(\mathrm{H}_{2} \mathrm{O}_{2}\right)$, and nitric oxide (NO) and PARS in the permeability and structure of small intestine $\mathrm{TJ}$ is not clearly understood.

Materials and Methods: In vitro study, MDCK (Madin-Darby Canine Kidney) cells were exposed to $\mathrm{H}_{2} \mathrm{O}_{2}(100 \mu \mathrm{M}$ for $2 \mathrm{~h})$, or zymosan $(200 \mu \mathrm{l}$ of stock solution $1 \mathrm{mg} / \mathrm{ml}$ for $4 \mathrm{~h})$, in the presence or absence of a treatment with poly(ADP-ribose) synthetase (PARS) inhibitor 3-aminobenzamide (3-AB: $3 \mathrm{mM}$ ) or with $n$-acetylcysteine (NAC $10 \mathrm{mM}$ ). In vivo study, wild-type mice (WT) and mice lacking (KO) of the inducible (or type 2) nitric oxide synthase (iNOS) were treated with zymosan (500 $\mathrm{mg} / \mathrm{kg}$, suspended in saline solution, i.p.). In addition INOSWT mice were treated with 3-AB (10 $\mathrm{mg} / \mathrm{kg}$, i.p.) or with NAC (40 mg/kg, i.p.) 1 hour and $6 \mathrm{~h}$ after zymosan administration.

Results: Exposure of MDCK cells to hydrogen peroxide caused a significant impairment in mitochondrial respiration that was associated with a reduction of cells adherence as well as derangement of the junctional proteins. A significant increase of nitrate and nitrite levels, stable metabolites of nitric oxide (NO), were found in MDCK supernatant after
\end{abstract}

\section{Introduction}

The mucosa of the digestive tract provides an effective barrier to the entry of intestinal bacte-

Address correspondence and reprint requests to: Salvatore Cuzzocrea PhD, Institute of Pharmacology, School of Medicine, University of Messina, Policlinico Universitario, Torre Biologica 98123 Messina Italy. Tel: (39)090-2213644 Fax: (39)090-2213300;

E-mail: salvator@www.unime.it zymosan incubation. NO production was associated with a significant reduction of cell adherence and impairment of occludin protein. Pre-treatment of the cells with 3-AB or with NAC caused a significant prevention of $\mathrm{H}_{2} \mathrm{O}_{2}$-mediated occludin junctional damage as well as reduced the NOinduced occludin damage. In addition, $\mathrm{H}_{2} \mathrm{O}_{2}$ and $\mathrm{NO}$ are able to induce a significant derangement of $\beta$-catenin and Zonula Ocludence-1 (ZO-1). We found an increase of tight junctional permeability to lanthanum nitrate (molecular weight, 433) in the terminal ileal TJs in zymosan-treated iNOSWT mice compared with permeableTJ in the control animals. Zymosan-treated iNOSKO mice showed a significant increase of tight junctional permselectivity. There were no differences in strand count or strand depth in the ilea from control or treated animals. In addition, a significant disrupted immunofluorescence signal for occludin, ZO- 1 and $\beta$-catenin was observed in the terminal ilea of zymosantreated iNOSWT mice. In ileal fragments from zymosan-treated iNOSKO mice, we found less irregular distribution patterns of occludin, ZO-1 and $\beta$-catenin. Similarly NAC or 3-AB treatments were able to prevent zymosan-induced damage of junctional proteins in iNOSWT mice.

Conclusion: In conclusion, this study demonstrates that the alteration of permselectivity is most likely induced by ROS and PARS activation. ria and endotoxins in healthy individuals. As has been shown in animal studies $(3,4)$, this barrier function can be lost during critical illness and, thus, may lead to translocation of bacteria and absorption of endotoxins into the circulation. Bacterial translocation may cause secondary infection of intra-abdominal inflammatory processes, such as intra-abdominal abscesses or sterile peritonitis (5). Moreover, 
translocation of bacteria and absorption of endotoxins may have profound systemic effects and may result in bacteremia, as well as endotoxemia. Endotoxins, in turn, increase the permeability of the digestive tract, thereby facilitating bacterial translocation and endotoxin absorption $(3,4)$. It is postulated that, in this way, the digestive tract can be the source of an ongoing septic state in patients without a defined infectious focus, thus, contributing to the development of multiple organ failure.

Zymosan is a nonbacterial, nonendotoxic agent that produces acute peritonitis and multiple organ failure characterized by functional and structural changes in liver, intestine, lung, and kidneys $(6,7)$. The organ dysfunction in zymosan-treated animals may be, in part, dependent on bacterial translocation $(6,7)$. We recently reported zymosan caused both signs of peritonitis and organ injury within $18 \mathrm{hr}$. The onset of the inflammatory response caused by zymosan in the peritoneal cavity was associated with systemic hypotension, high peritoneal and plasma levels of NO, maximal cellular infiltration, exudate formation, and cyclooxygenase activity $(8,9)$. In addition, we recently discovered that injection of zymosan into the rat resulted in excessive reactive oxygen species (ROS) formation, as well as a related species, such as peroxynitrite by activated polymorphonuclear cells (PMNs) or lipid peroxidation in plasma, intestine, and lung $(6,8,9)$.

It was demonstrated recently that large amounts of NO induced an increase in paracellular permeability in intestinal epithelial cells in vitro (10). Moreover, in immunostimulated intestinal epithelial cells, the increase in transepithelial permeability was diminished by inhibitors of nitric oxide synthase (NOS) (11).

Epithelial and endothelial cell sheets form semipermeable barriers to the passage of cells, molecules, and ions across two compartments of the extracellular space. To achieve this barrier function, cells develop a circumferential seal around the apical pole of the cell, which is part of the junctional complex (12) and is called the tight junction (TJ) or zonula occludens. TJ finely regulate the passage of molecules through the paracellular pathway (gate function) and are also located precisely at the boundary between distinct apical and basolateral domains of the plasma membranes of polarized epithelial and endothelial cells (fence function). Thus, TJ have a key role in the func- tion of all epithelia involved with polarized secretion or absorption and in the formation of barriers between different tissue and organ compartments. Furthermore, TJ can be targets of toxins. TJ modulation may be important in the pathogenesis of disease and in the therapeutic delivery of drugs across physiological barriers (13-16). As a result, TJ have been studied extensively at the morphological, functional, and molecular levels. Several studies have elucidated the molecular structure of $\mathrm{TJ}$ (17-19). The transmembrane portion of TJ contains at least two distinct sets of integral membrane proteins, occludin (Mr 58-82 kD) (20), and claudins (Mr $22 \mathrm{kD})(21)$.

ROS produce cellular injury and necrosis via several mechanisms, including peroxidation of membrane lipids, protein denaturation, and DNA damage (22). Evidence from studies utilizing cultured cells have demonstrated that ROS produce strand breaks in DNA that trigger the activation of the nuclear enzyme poly(ADPribose) synthetase (PARS) (23). PARS is an abundant, chromatin-bound enzyme constitutively expressed in most cell types (24). It is an energy-consuming enzyme thought to be involved in DNA repair (23), although its true physiological role is still unclear (24). Once activated, PARS catalyzes the transfer of ADPribose moieties from NAD to nuclear proteins, including histones, and onto PARS itself (automodification), with the concomitant formation of nicotinamide (26). However, there is now good evidence that exposure of cells to oxidant stress (e.g. $\mathrm{H}_{2} \mathrm{O}_{2}$, peroxynitrite, etc.) results in strand breaks in DNA, leading to an excessive activation of PARS that results in the depletion of its substrate NAD in vitro and a reduction in the rate of glycolysis (27-28). As NAD functions as a cofactor in glycolysis and the tricarboxylic acid cycle, NAD depletion leads to a rapid fall in intracellular ATP levels (29-32). Furthermore, nicotinamide formed by PARS activation can be recycled back to NAD via a mechanism that also consumes ATP (30). Thus, activation of PARS leads to a fall in ATP via two different mechanisms, leading to cellular dysfunction and ultimately cell death. Overall, this process has been termed the "PARS Suicide Hypothesis" (32).

Here, by comparing the responses in wildtype mice (WT) and mice lacking (KO) the inducible (or type 2) nitric oxide synthase (iNOS), we investigated the role played by iNOS and PARS in the distribution of the junc- 
tion proteins (occludin, (ZO-1), and $\beta$-catenin), as well as in the intestinal permeability during acute peritonitis caused by zymosan. To better understand the mechanisms of the observed effects, we also investigated in vitro, using Madin-Darby Canine Kidney (MDCK) cells, whether TJ derangement is caused by oxidant stress (hydrogen peroxide) and PARS activation.

\section{Materials and Methods}

\section{Materials}

Zambon Italia, Bresso, (MI), Italy supplied $n$ acetylcysteine. Rabbit polyclonal C-terminal antioccludin antibody, rabbit polyclonal $\beta$-catenin antibody, and rabbit polyclonal anti-ZO- 1 antibody were obtained from Zymed Laboratories (Milan, Italy). All other reagents and compounds used were obtained from Sigma Chemical Company (Sigma, Milan, Italy).

\section{Animals}

Male iNOS KO and iNOS WT mice (20-25 g, kindly supplied by Fons A.J. Van de Loo, Dep. Of Rheumatology, University Hospital Nijmegen, Nijmegen, The Netherlands) were allowed access to food and water ad libitum. Animal care was in compliance with Italian regulations on protection of animals used for experimental and other scientific purposes (D.M., 116192), as well as with the European Economic Community (EEC) regulations (O.J. of E.C., L 358/1 12/18/1986).

\section{In vivo Studies}

Animals were randomly divided into six groups ( $n=10$ for each group). The first group (iNOS WT) was treated with saline solution $(0.9 \% \mathrm{NaCl})$ intraperitoneally (i.p.) and served as the sham group. The second group (iNOS WT) was treated with zymosan $(500 \mathrm{mg} / \mathrm{kg}$, suspended in saline solution, i.p.). In the third and forth groups, iNOS KO mice received saline or zymosan administration, respectively. In the fifth and sixth groups, iNOS WT were treated with 3-amino benzamide (3-AB; 10 $\mathrm{mg} / \mathrm{kg}$ i.p.) $1 \mathrm{hr}$ and $6 \mathrm{hr}$ after zymosan or saline administration. In the seventh and eighth sixth groups, iNOS WT were treated with (NAC; $40 \mathrm{mg} / \mathrm{kg}$ i.p.) $1 \mathrm{hr}$ and $6 \mathrm{hr}$ after zymosan or saline administration. The times of treatments were in agreements with our recent publications $(9,33)$.

\section{Cell Culture}

MDCK (Madin-Darby Canine Kidney) cells were cultured in Dulbecco's Modified Eagle Medium (DMEM) supplemented with Lglutamine $(3.5 \mathrm{mM})$, penicillin $(50 \mathrm{U} / \mathrm{ml})$, streptomycin $(50 \mu \mathrm{g} / \mathrm{ml})$, and heparin sodium $(10 \mathrm{U} / \mathrm{ml})$ in 6 -well plates at $37^{\circ} \mathrm{C}$ in a humidified $5 \% \mathrm{CO}_{2}$ incubator until $90 \%$ confluence. Cells were exposed to hydrogen peroxide (100 $\mu \mathrm{M}$ for $\mathbf{2} \mathrm{hr})$, or zymosan (200 $\mu \mathrm{l}$ of stock solution $1 \mathrm{mg} / \mathrm{ml}$ for $4 \mathrm{hr}$ ), in the presence or absence of a treatment with $(3-\mathrm{AB} ; 3 \mathrm{mM})$ or NAC (10 mM).

\section{Measurement of Nitrite/Nitrate}

Nitrite + nitrate production, an indicator of NO synthesis, was measured in the supernatant samples as previously described (33). Briefly, the nitrate in the supernatant was reduced to nitrite by incubation with nitrate reductase (670 $\mathrm{mU}^{-\mathrm{ml}^{-1}}$ ) and $\beta$-nicotinamide adenine dinucleotide phosphate (NADPH; $160 \mu \mathrm{M}$ ) at room temperature for $3 \mathrm{hr}$. The nitrite concentration in the samples was measured by the Griess reaction by adding $100 \mu \mathrm{l}$ of Griess reagent $(0.1 \%$ naphthylethylendiamide dihydrochloride in $\mathrm{H}_{2} \mathrm{O}$ and $1 \%$ sulphanilamide in $5 \%$ concentrated $\mathrm{H}_{3} \mathrm{PO}_{4}$; vol. $\left.1: 1\right)$ to $100-\mu \mathrm{l}$ samples. The optical density at $550 \mathrm{~nm}\left(\mathrm{OD}_{550}\right)$ was measured using an ELISA microplate reader (SLT-Labinstruments, Salzburg, Austria). Nitrate concentrations were calculated by comparison with $\mathrm{OD}_{550}$ of standard solutions of DMEM.

\section{Measurement of Mitochondrial Respiration}

Cell respiration was assessed by measuring the mitochondrial-dependent reduction of MTT [3(4,5-dimethylthiazol-2-yl)-2,5-diphenyltetrazolium bromide] to formazan (33). Cells in 96-well plates were incubated at $37^{\circ} \mathrm{C}$ with MTT $(0.2 \mathrm{mg} / \mathrm{ml})$ for $1 \mathrm{hr}$. Culture medium was removed by aspiration and the cells were solubilized in dimethyl sulfoxide (DMSO; $100 \mu \mathrm{l}$ ). The extent of reduction of MTT to formazan within cells was quantified by the measurement of $\mathrm{OD}_{550}$. As previously discussed (25), the measurement of MTT reduction appeared to involve mainly the mitochondrial complexes I and II, but may also have involved nicotineamide adenine dinucleotide (NADH)and NADPH-dependent energetic processes that occurred outside the mitochondrial inner 
membrane. Thus, this method could not be used to separate the effect of free radicals, oxidants, or other factors on the individual enzymes in the mitochondrial respiratory chain, but was useful to monitor changes in the general energetic status of the cells (33).

\section{Transmission Electron Microscopy}

After fixation, the specimens were rinsed for 30 min in $0.1 \mathrm{~m}$ cacodylate buffer and $4 \%$ lanthanum nitrate (molecular weight, 433.02) and postfixed for $1 \mathrm{hr}$ at $4^{\circ} \mathrm{C}$ in $1 \%$ osmium tetroxide, containing $4 \%$ lanthanum nitrate (Società Italiana Chimici, Rome, Italy). Subsequently, the tissue samples were dehydrated by graded ethanol and embedded in Agar 100. Fragments were cut in 100- $\AA$ sections with a Ultramicrotome System 2128 (Ultratome, Bromme, Germany) and examined in a Hitachi H-600 (Tokyo, Japan) at $50 \mathrm{kV}$, at a magnification of $35,000 \mathrm{X}$. From each animal, 150 to 250 consecutive TJ were observed, avoiding those next to goblet cells, which were known to have minor resistance (34). TJ were regarded as having increased permeability when the electrondense marker penetrated into the junctional complex and electrondense material was identified on the luminal surface (35).

\section{Freeze Fractures}

The ileum from the different groups of animals was fixed in $2 \%$ glutaraldehyde in $0.1 \mathrm{M}$ cacodylate buffer for $30 \mathrm{~min}$ and conserved at $4^{\circ} \mathrm{C}$ in $0.1 \mathrm{M}$ cacodylate buffer in the presence of $3 \mathrm{M}$ sucrose to avoid crystallization (Società Italiana Chimici, Rome, Italy). Fracturing of the apical portion of the intestinal villi was performed at $-100^{\circ} \mathrm{C}$ in a vacuum chamber (Baizers Instruments, Liechtenstein). The specimens were shadowed with platinum/carbon vapor with an angle of $45^{\circ}$, followed by carbon. Replicas were cleaned with commercial bleach, mounted on copper grids, and observed in a Hitachi $\mathrm{H}-600$ at $50 \mathrm{kV}$, at a magnification of $100,000 \mathrm{X}$. The average strand number and depth were recorded for each sample, observing at least 10 evaluable freeze fractures. Again, fractures next to goblet cells were not considered.

\section{Immunohistochemistry}

Indirect immunofluorescence staining was performed on $7-\mu \mathrm{m}$-thick sections of unfixed tissue specimens. Sections were cut with a Slee \& London (Wetziar, Germany) cryostat at $-27^{\circ} \mathrm{C}$, transferred onto clean glass slides, and dried overnight at room temperature. Sections were permeabilized with acetone at $-20^{\circ} \mathrm{C}$ for $10 \mathrm{~min}$ and rehydrated with phosphate buffered saline (PBS; $150 \mathrm{mM}$ NaCI, $20 \mathrm{mM}$, sodium phosphate, $\mathrm{pH}$ 7.2) at room temperature for $45 \mathrm{~min}$. Sections were incubated with rabbit polyclonal C-terminal anti-occludin antibody [1:500 in PBS, volume per volume (v/v), Zymed Laboratories, San Francisco, CA], or with rabbit polyclonal $\beta$-catenin antibody (1:500 in PBS, v/v; Zymed Laboratories, San Francisco, CA), or with rabbit polyclonal antiZO-1 antibody raised against a 69-kcl fusion protein (1:500 in PBS, v/v; Zymed Laboratories) in a humidified chamber for $1 \mathrm{hr}$ at $37^{\circ} \mathrm{C}$. Sections were washed with PBS and incubated with secondary antibody (FITC)-conjugated goat anti-rabbit antibody; 1:80 in PBS, v/v; Jackson, West Grove, PA) for $1 \mathrm{hr}$ at $37^{\circ} \mathrm{C}$. Sections were washed as before, mounted with $\mathbf{9 0} \%$ glycerol in PBS, and observed with a laser scanning microscope (LSM 510 Zeiss, Milan, Italy).

\section{Measurement of Intestinal Permeability}

After a midline abdominal incision, $3 \mathrm{ml}$ warmed saline was poured into the abdominal cavity. Then, a segment of the terminal ileum (approx. $800 \mathrm{mg}$ ) supplied by 3 blood vessel arcades was isolated from the remaining part of the intestine by incising the mesentery and transsecting the bowel wall between two aneurysm clips. Proximal and distal to the clips, the gut lumen was closed by placing purse string sutures. The segment used for permeability measurements was cannulated at both ends and its luminal content was gently flushed with warmed saline $(10 \mathrm{ml})$ from oral to aboral direction and the distal end was closed with a suture. Intestinal permeability (lumen to plasma) was measured using a 4000 Da fluorescent dextran (FD4), according to previously described methods $(36,37)$. After cannulation of the femoral vessels, a continuous infusion of saline was started at a rate of 2.5 $\mathrm{ml} / \mathrm{hr}$. The renal vessels were ligated and the segment was filled up with $0.5 \mathrm{ml}$ warmed FD4 solution $(25 \mathrm{mg} / \mathrm{ml})$. After $10 \mathrm{~min}, 0.3 \mathrm{ml}$ blood samples were taken for fluorescein concentration measurements in the plasma. At the end of the experiment, the bowel segment was removed and weighed. 

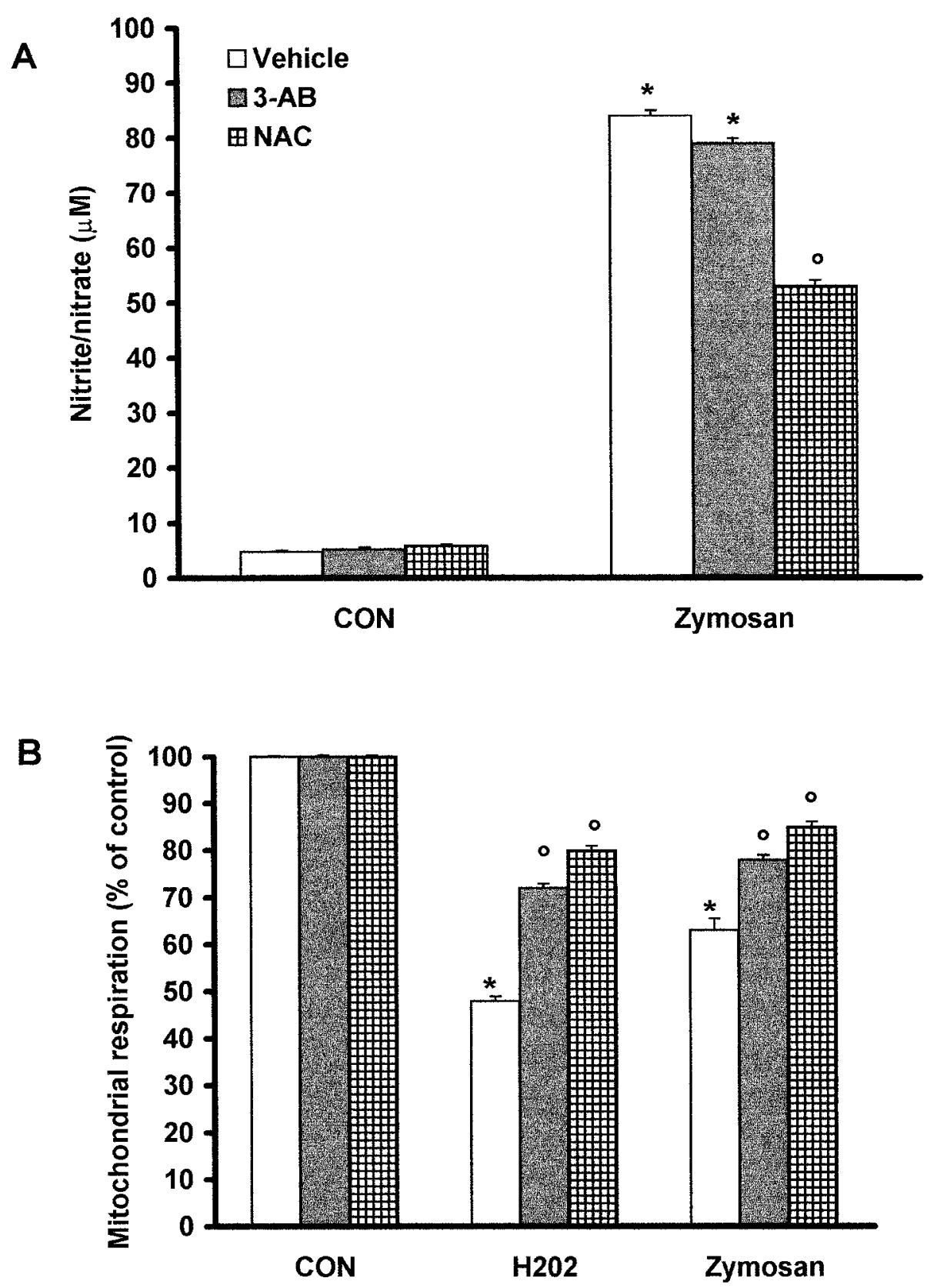

Fig. 1. Effect of NAC (10 mM) and 3-AB (3 mM). (A) Effects on nitrate/nitrite production and (B) reduction of mitochondrial respiration in Madin-Darby Canine Kidney cells (MDCK) treated with $\mathrm{H}_{2} \mathrm{O}_{2}-(100 \mu \mathrm{M}$ for $2 \mathrm{~h}$ ) or zymosan

two TJ-associated proteins (occludin and ZO1) we investigated, the transmembrane protein occludin did show a disrupted immunofluorescence signal, together with an irregular distribution pattern in the terminal ilea of mice with zymosan-peritonitis. To our knowledge, this is the first report on occludin alterations of small intestine $\mathrm{TJ}$ in experimental peritonitis. In the
(200 $\mu \mathrm{l}$ of stock solution $1 \mathrm{mg} / \mathrm{ml}$, for $4 \mathrm{hr}$ ). ${ }^{*} p 0.01$ versus control; ${ }^{\circ} p<0.01$ versus treated cells. NAC, $n$-acetycysteine; $3-\mathrm{AB}$, 3-amino benzamide. present study, we added freeze fracture replica analysis and immunohistochemistry of occludin to detect ultrastructural changes induced by inflammation. The junctional strands are believed to represent the transmembranous portion of occludin (38); whereas, cingulin and ZO-1 belong to the intracellular domain of TJ $(39,40)$. Thus, our present data may seem 

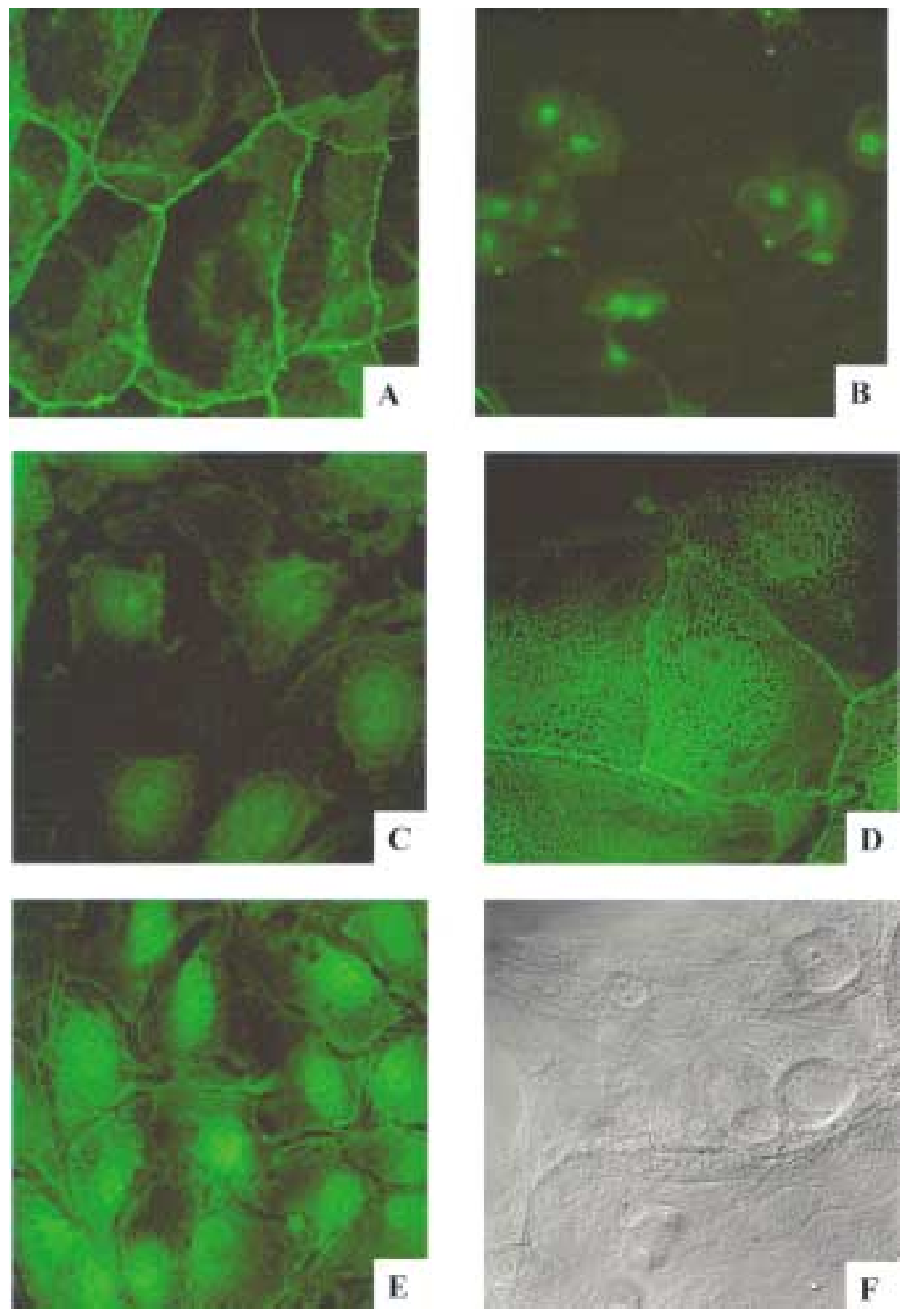

Fig 2. Indirect immunofluorescence of occludin in the MDCK. (A) Control cells; (B) cells exposed to $\mathrm{H}_{2} \mathrm{O}_{2}(100 \mu \mathrm{M}$, for $2 \mathrm{hr})$; (C) cells exposed to zymosan $(200 \mu \mathrm{l}$ of stock solution $1 \mathrm{mg} / \mathrm{ml}$, for $4 \mathrm{hr}$ ); (D) $\mathrm{H}_{2} \mathrm{O}_{2}$-exposed cells incubated with 3- $\mathrm{AB}(3 \mathrm{mM}) ;(\mathrm{E}) \mathrm{H}_{2} \mathrm{O}_{2}$ -

contradictory in view of a disturbed occludin signal. In a very recent study, however, it was shown that occludin-deficient embryonic stem cells were able to differentiate into polarized epithelial cells exhibiting well-developed continuous and anastomosing TJ strands (41).

exposed cells incubated with NAC (10 mM); (F) represent the transmission light of control cells. MDCK, Madin-Darby Canine Kidney cells; 3-AB, 3-aminobenzamide; NAC, $n$-acetylcysteine.

Moreover, studies on MDCK cells expressing COOH-terminally truncated chicken occludin revealed a normal appearance of fibrils obtained by freeze-fracturing, despite a discontinuous immunostaining pattern of occludin, together with an enhanced permeability to dextran (42). 


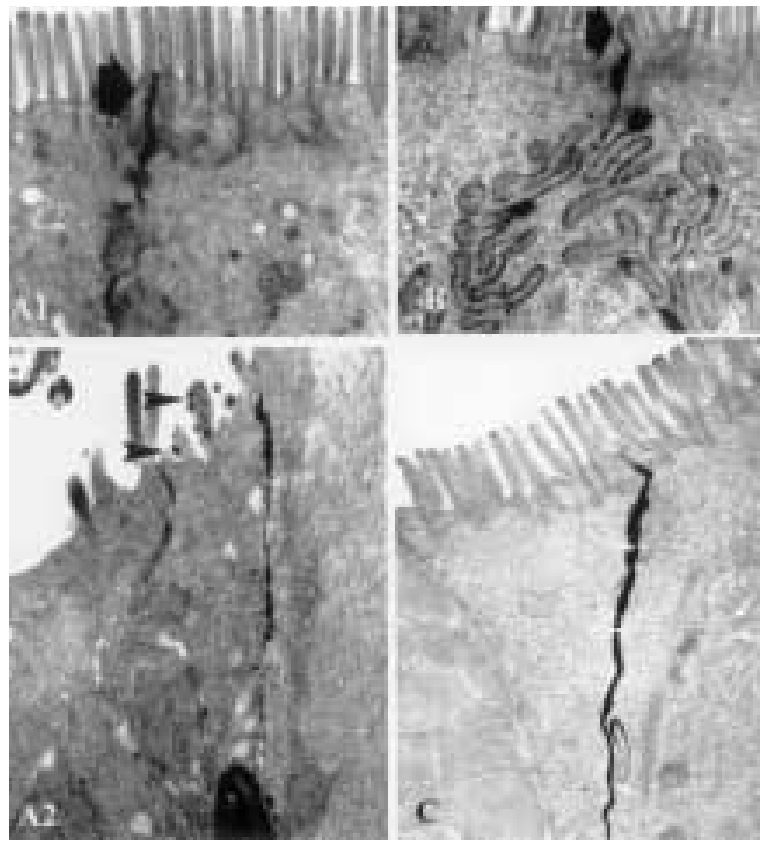

Fig. 3. Electron microscopy of ileum TJ perfused lanthanum nitrate. Ileum from iNOS WTtreated with zymosan $(500 \mathrm{mg} / \mathrm{kg} / \mathrm{i} . \mathrm{p}$.) shows penetration of lanthanum nitrate (see arrow) within the junctional complex (Al) and deposition of the electron-dense marker between the microvilli (see arrowheads; A2). Ileum from shamoperated iNOS WT mice (B) and in zymosantreated iNOS KO mice (C) shows intact junctional complex and demonstrates that the lanthanum marker (arrow) is accumulated under the TJ complex. Original magnification 40,000 X. $\mathrm{TJ}$, tight junction; iNOS, inducible nitric oxide synthase; WT, wild type; KO, mice lacking iNOS.

Thus, also in view of the recently identified novel integral membrane proteins (43), a normal appearance of anastomosing fibrils obtained by freeze-fracturing does not necessarily imply a normal occludin pattern. In addition, Tsukita and Furase (44) showed, using immunogold in free fracture, that claudin colocalized in TJ strands. The observed alterations are more likely the result of the following factors: (a) circulating or locally produced proinflammatory substances, or (b) release of free radicals. Reactive oxygen free radicals (ROS) have been shown to play a significant role in inflammatory reactions (45). These highly reactive agents, especially the hydroxyl radical, can initiate cell membrane lipid peroxidation, thereby, damaging the membrane integrity. ROS also react with proteinaceous materials in the plasma to produce chemotactic materials
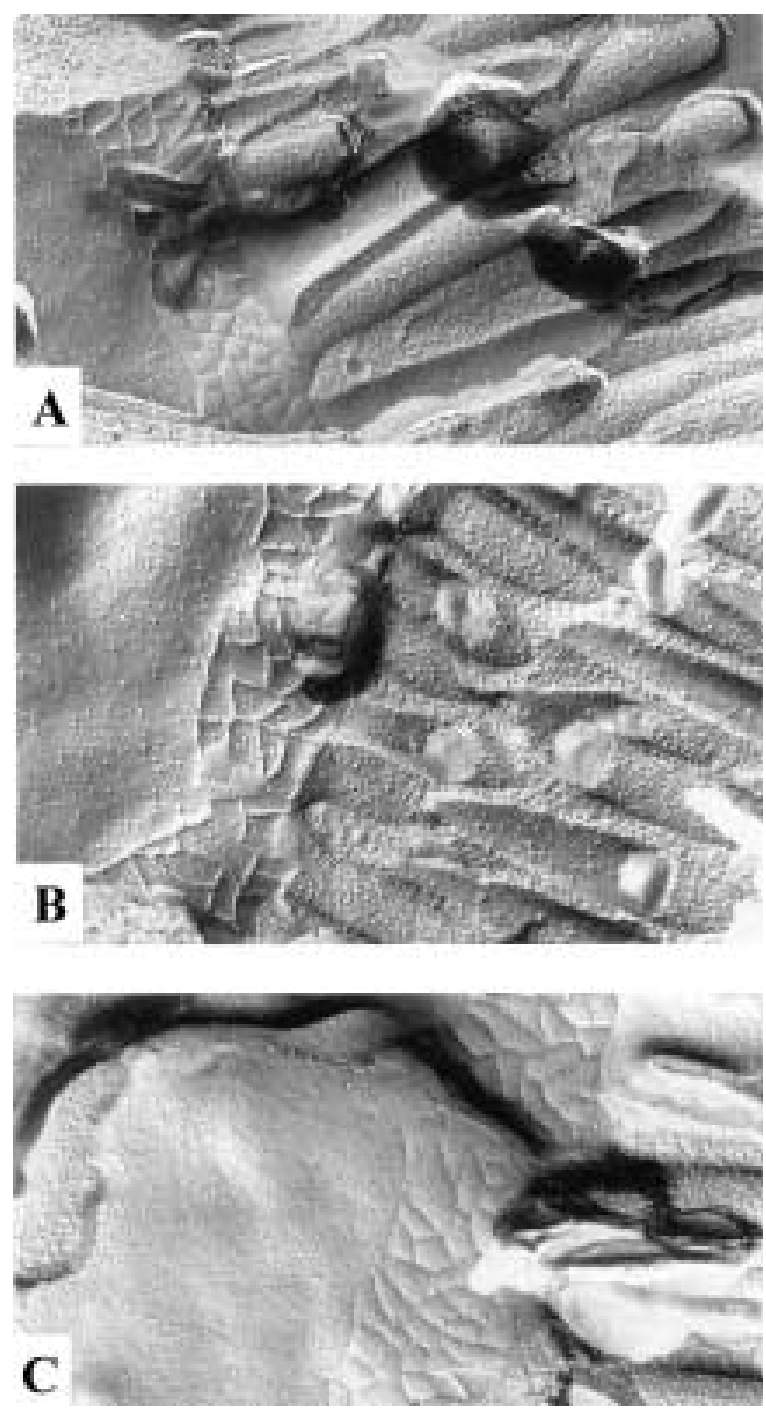

Fig. 4. Freeze-fracture replicas. (A) Of shamoperated iNOS WT mice, (B) zymosan-treated iNOS WT mice, and (C) zymosan-treated iNOS KO mice. There are no differences in strand number or depth in ileum. Original magnification 68,000 X. iNOS, inducible nitric oxide synthase; WT, wild type; $\mathrm{KO}$, mice lacking iNOS.

that attract phagocytes and lymphocytes into the area of injury (46). ROS may also change microvascular permeability by causing an activation of the contractile mechanism of endothelial cells (47).

We recently discovered that injection of zymosan into the experimental animals resulted in excessive ROS formation by activated polymorphonuclear cells (PMNs), as well as lipid peroxidation in plasma, intestine, liver, and lung (33). A variety of endogenous substances exist to protect the cell from active radical damage. The three most important anti- 

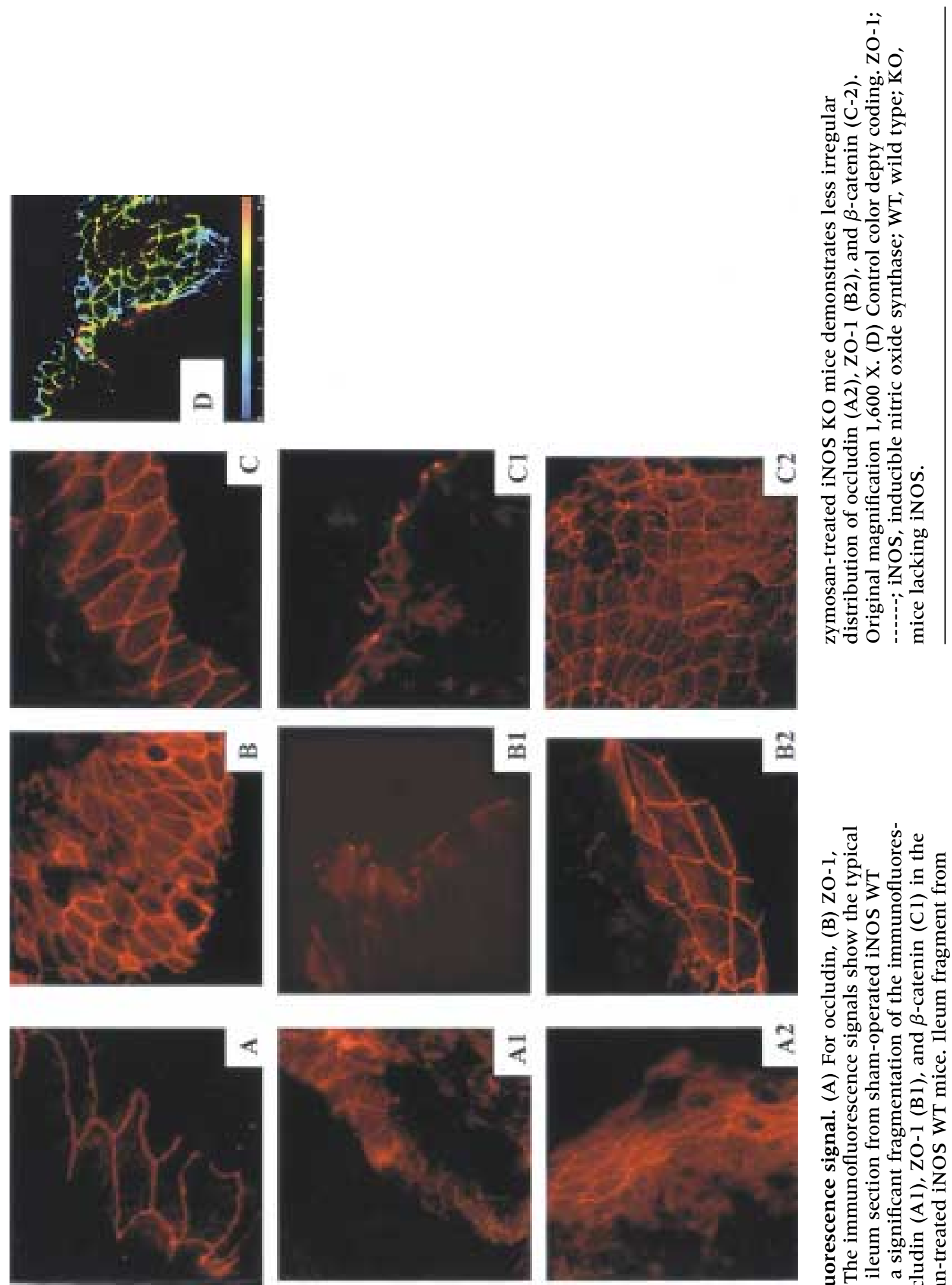

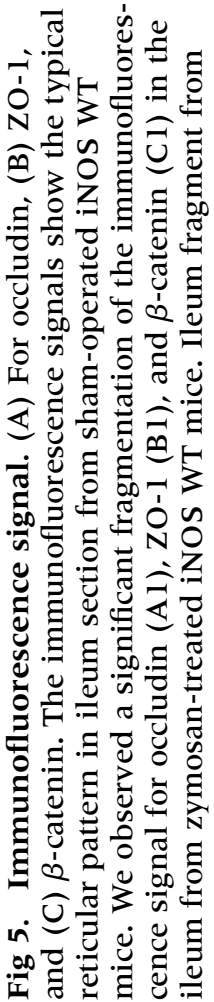




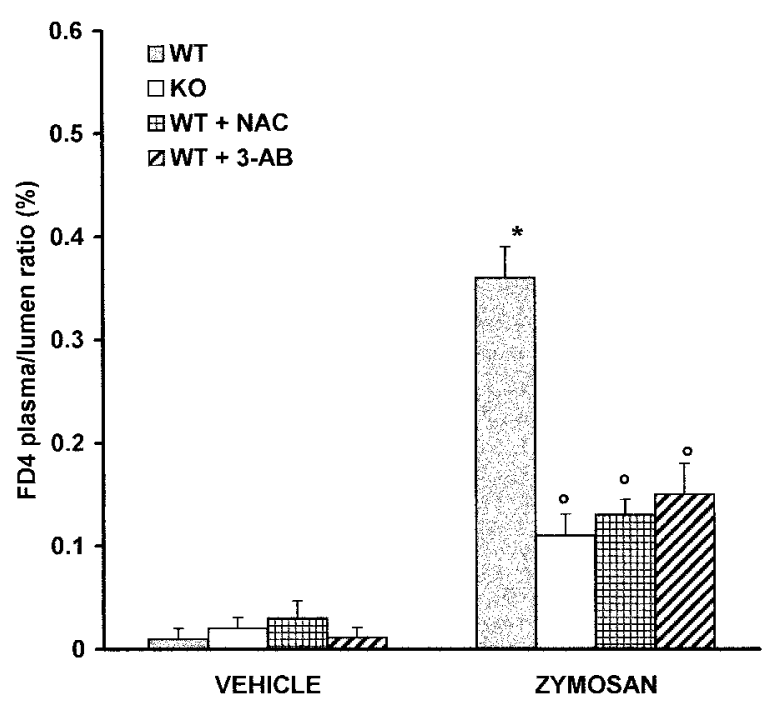

Fig. 6. Plasma/lumen ratio of FD4, an indicator of intestinal epithelial permeability, in the intestine of zymosan-treated mice. Epithelial permeability significantly increased in zymosan-treated iNOS WT mice. Zymosantreated iNOS KO mice and iNOS WT mice treated with NAC or 3-AB showed a significant reduction in the increase in permeability. Each value is the mean \pm standard error of the mean (SEM) for $n=10$ animals. ${ }^{*} p<0.01$ vs. sham; ${ }^{\circ} p<0.01$ vs. zymosan-treated iNOS WT. iNOS, inducible nitric oxide synthase; WT, wild type; $\mathrm{KO}$, mice lacking iNOS; NAC, $n$-acetylcysteine.

oxidants are superoxide dismutase, catalase, and reduced glutathione $(48,49)$.

Interventions that reduce the generation or the effects of ROS exert beneficial effects in a variety of models of inflammation, including the zymosan-induced peritonitis model used here. These therapeutic interventions include melatonin (50) and superoxide dismutasemimetic $(49,51)$.

ROS produce cellular injury and necrosis via several mechanisms, including peroxidation of membrane lipids, protein denaturation, and DNA damage. ROS produce strand breaks in DNA that trigger energy-consuming DNA repair mechanisms and activate the nuclear enzyme PARS, resulting in the depletion of its substrate nicotinamide adenine dinucleotide (NAD) in vitro and a reduction in the rate of glycolysis. As NAD functions as a cofactor in glycolysis and the tricarboxylic acid cycle, NAD depletion leads to a rapid fall in intracellular ATP. This process has been termed "the PARS Suicide Hypothesis." There is recent evidence that the activation of PARS may also play an important role in shock and inflamma- tion $(52,53)$. Therefore, it was observed recently that exposed endothelia and epithelial cells to $\mathrm{H}_{2} \mathrm{O}_{2}$ result in ADP-ribosylation, $\mathrm{NAD}^{+}$depletion, inhibition of mitochondrial respiration, and increased paracellular permeability. 3-AB provides a significant, partial protection against the energetic and functional changes $(54,55)$.

To our knowledge, this is the first report that point out a key role of $\mathrm{NO}, \mathrm{H}_{2} \mathrm{O}_{2}$ and PARS on permselectivity alterations of small intestine TJ. It has been demonstrated that interferon- $\gamma$ and tumor necrosis factor- $\alpha$ increase permeability in both epithelial and endothelial cells in vitro, most probably through dynamic cytoskeletal alterations (56). Finally, there is a substantial body of prior work implicating the role of oxyradicals in the pathogenesis of endothelial and epithelial injury in ischemiareperfusion, shock, and inflammation $(36,54,57)$. More recently, it was suggested that NO derived from the endothelium or from other sources may combine with superoxide, to form peroxynitrite, which in turn, may exert cytotoxic effects to the endothelial cells $(36,54,57,58)$. Moreover, under conditions of intracellular L-arginine depletion, NOS itself may produce cytotoxic amounts of peroxynitrite (59). Furthermore, PARS activation has been involved in the ROS and peroxynitrite-induced acute and delayed cytotoxicity in endothelial and epithelia cells.

In conclusion, this study demonstrates that the alteration of permselectivity is most likely induced by ROS and PARS activation. Similarly, pretreatment of MDCK cells or wild-type mice with NAC or 3-AB reduces the junctional damage. These findings support the view that ROS and PARS contribute to the extension of permselectivity in the model of zymosaninduced peritonitis used here. The mechanisms of the ROS and PARS on the junctional modification are not entirely clear. It appears that the inflammatory process augments (positive feed-back; Fig. 7) the formation of proinflammatory cytokines, which in turn may augment the recruitment of neutrophils, the expression of iNOS and cyclooxygenase-2 (COX-2) protein and activity and, ultimately, the degree of ROS formation and intestinal permeability. In addition, ROS appears to activate the suicide cycle of PARS, which in turn, may contribute to the junctional damage. Finally, our findings suggest that interventions that may reduce the generation or the effects of ROS may be useful in conditions associated with inflammation. 


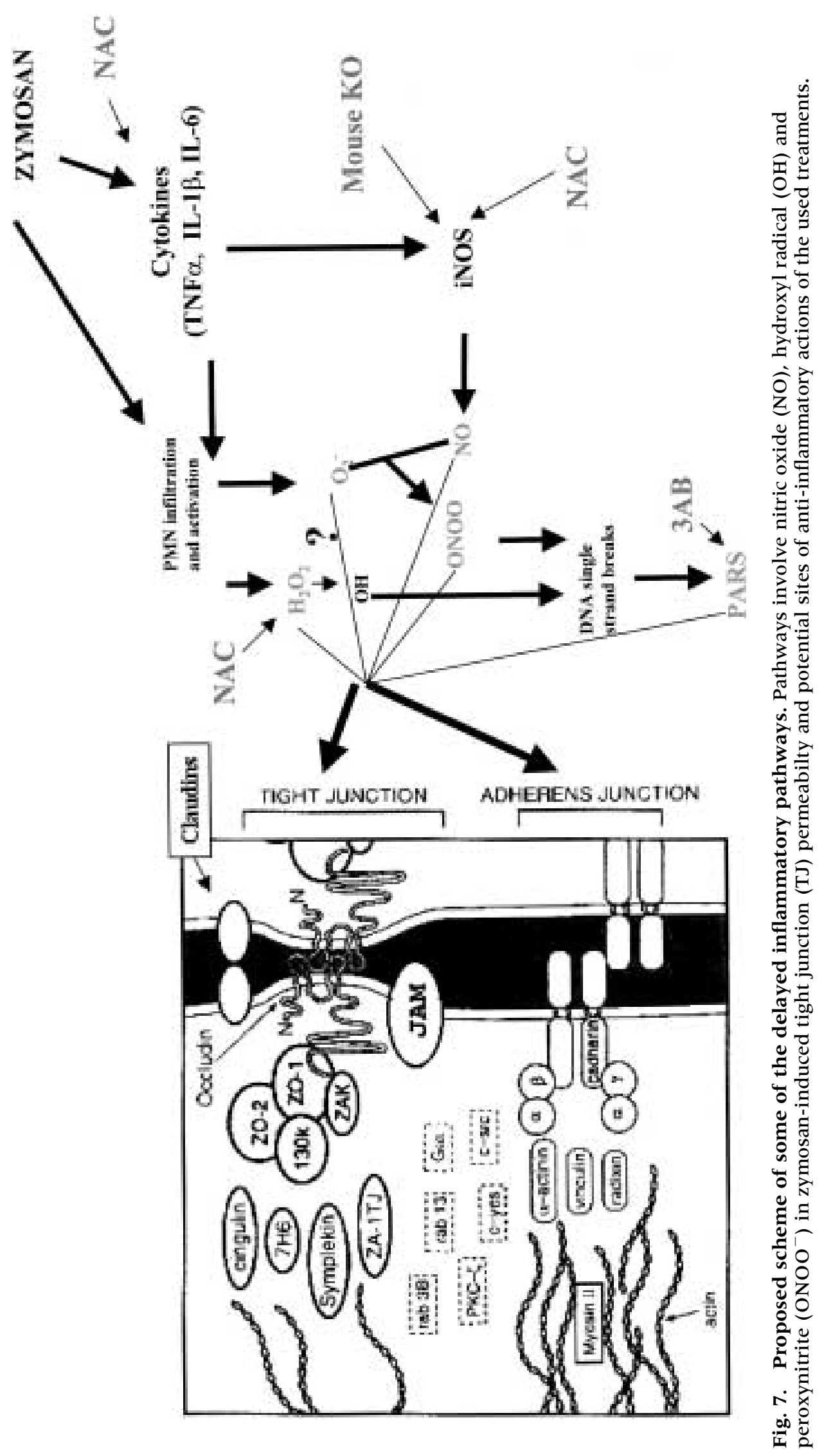




\section{References}

1. Gardiner KR, Halliday MI, Barclay GR, et al. (1995) Significance of systemic endotoxaemia in inflammatory bowel disease. Gut 36: 897-901.

2. Jennings G, Lunn PG, Elia M. (1995) The effect of endotoxin on gastrointestinal transit time and intestinal permeability. Clin. Nutr. 14: 3541.

3. Deitch EA, Berg R, Specian R. (1987) Endotoxin promotes the translocation of bacteria from the gut. Arch. Surg. 122: 1850-190.

4. Fink MP. (1991) Gastrointestinal mucosal injury in experimental models of shock, trauma, and sepsis. Crit. Care Med. 19: 627-41.

5. Goris RJ, Boekholtz WK, van Bebber IP, Nuytinck JK, Schillings PH. (1986) Multiple-organ failure and sepsis without bacteria. An experimental model. Arch. Surg. 121: 897-901.

6. Goris RJ, Van Bebber IPT, Mollen RMH, Koopman JP. (1991) Does selective decontamination of the gastrointestinal tract prevent multiple organ failure? Arch. Surg. 126: 561-572.

7. Mainous MR, Ertel W, Chaudry IH, Deitch EA. (1995) The gut: a cytokine-generating organ in systemic inflammation? Shock 4: 193-200.

8. Cuzzocrea S, Filippelli A, Zingarelli B, Falciani M, Caputi AP, Rossi F. (1997) Role of nitric oxide in a non-septic shock model induced by zymosan in the rat. Shock 7: 351-358.

9. Cuzzocrea S, Zingarelli B, Costantino G, Sottile A, Teti D, Caputi AP. (1999) Protective effect of poly (ADP-Ribose) synthetase inhibition on multiple organ failure following zymosan-induced peritonitis. Crit. Care Med. 27: 1517-23.

10. Salzman AL, Menconi MJ, Unno N, et al. (1995) Nitric oxide dilates tight junctions and depletes ATP in cultured Caco-2BBe intestinal epithelial monolayers. Am. J. Physiol. 268: G361-G373.

11. Unno N, Menconi M, Smith M, Fink MP. (1995) Nitric oxide mediates interferon $-\gamma$ induced hyperpermeability in cultured human intestinal epithelial monolayers. Crit. Care Med. 23: 11701176.

12. Farquhar MG, Palade GE. (1963) Junctional complexes in various epithelia. J. Cell. Biol. 17: 375412.

13. De Boer AG, Breimer DD. (1994) The bloodbrain barrier: clinical implications for drug delivery to the brain. J. R. Coll. Physicians Lond. 28: 502-506.

14. Schneeberger E. (1994) Tight junctions: their modulation under physiological and pathological states. In: Citi S (ed.) Molecular Mechanisms of Epithelial Cell Junc-tions: From Development to Disease. RG Landes Biomedical Publishers, Austin, TX, pp. 123-140.

15. Fasano A, Baudry B, Pumplin DW, Wasserman SS, Ketley JM, Kaper JB. (1991) Vibrio cholerae produces a second enterotoxin, which affects intestinal tight junctions. Proc. Natl. Acad. Sci. U.S.A. 88: 5242-5246.

16. Madsen KL, Lewis SA, Tavernini MM, Hibbard J, Fedorak RN. (1997) Interleukin 10 prevents cytokine-induced disruption of T84 monolayer barrier integrity and limits chloride secretion. Gastroenterology 113: 151-159.

17. Citi S, Cordenonsi M. (1998) Tight junction proteins. Biochim. Biophys. Acta 1448: 1-11.

18. Mitic LL, Anderson JM. (1998) Molecular architecture of tight junctions. Annu. Rev. Physiol. 60: 121-142.

19. Stevenson BR, Keon BH. (1998) The tight junction: morphology to molecules. Annu. Rev. Cell. Dev. Biol. 14: 89-109.

20. Furuse M, Hirase T, Itoh M, et al. (1993) Occludin: a novel integral membrane protein localizing at tight junctions. J. Cell. Biol. 123: 1777- 1788.

21. Furuse M, Itoh M, Hirase T, et al. (1994) Direct association of occludin with $\mathrm{ZO}-1$ and its possible involvement in the localization of occludin at tight junctions. J. Cell. Biol. 127: 16171626.

22. Kloner RA, Przyklenk K, Whittaker P. (1989) Deleterious effects of oxygen radicals in ischemia/ reperfusion. Resolved and unresolved issues. Circulation 80: 1115-1127.

23. Oei SL, Griesenbeck J, Schweiger M. (1997) The role of poly (ADP-ribosyl)ation. Rev. Physiol. Biochem. Pharmacol. 131: 127-173.

24. Ikai K, Ueda K. (1983) Immunohistochemical demonstration of poly (adenosine diphosphateribose) synthetase in bovine tissues. J. Histochem. Cytochem. 31: 1261-1264.

25. De Murcia JM, Niedergang C, Trucco C, et al. (1997) Requirement of poly (ADP-ribose) polymerase in recovery from DNA damage in mice and in cells. Proc. Natl. Acad. Sci. U.S.A. 94: 73037307.

26. Ueda K, Hayaishi O. (1985) ADP-ribosylation. Ann. Rev. Biochem. 54: 73-100.

27. Schraufstatter IU, Hinshaw DB, Hyslop PA, Spragg RG, Cochrane CG. (1986) Oxidant injury of cells: DNA strand-breaks activate polyadenosine diphosphate-ribose polymerase and lead to depletion of nicotinamide adenine dinucleotide. J. Clin. Invest. 77: 1312-1320

28. Satoh M, Lindahl T. (1992) Role of poly (ADPribose) formation in DNA repair. Nature 356: $356-$ 358.

29. Carson DA, Seto S, Wasson B, Carrera CJ. (1986) DNA strand breaks, NAD metabolism and programmed cell death. Exp. Cell. Res. 164: 273281.

30. Hyslop PA, Hinshaw DB, Halsey WA, et al. (1988) Mechanisms of oxidant-mediated cell injury: the glycolytic and mitochondrial pathways of ADP phosphorylation are major intracellular targets inactivated by hydrogen peroxide. J. Biol. Chem. 263: 1665-1675. 
31. Thies RL, Autor AP. (1991) Reactive oxygen injury to cultured pulmonary artery endothelial cells: mediation by poly (ADP-ribose) polymerase activation causing NAD depletion and altered energy balance. Arch. Biochem. Biophys. 286: 353-363.

32. Berger NA. (1985) Poly (ADP-ribose) in the cellular response to DNA damage. Rad. Res. 101: 4-15.

33. Cuzzocrea S, Costantino G, Mazzon E, Caputi AP. (1999) Protective effect of $\mathrm{N}$-acetylcysteine on multiple organ failure induced by zymosan in the rat. Crit. Care Med. 27: 1524-1532.

34. Madara JL, Trier JS. (1982) Structure and permeability of goblet cell tight junctions in rat small intestine. J. Membr. Biol. 66: 145-157.

35. Lora L, Mazzon E, Martines D, et al. (1997) Hepatocyte tight-junctional permeability is increased in rat experimental colitis. Gastroenterology 113: 1347-1354.

36. Otamiri T, Lindal M, Tagesson C. (1988) Phospholipase A2 inhibition prevents mucosal damage associated with small intestinal ischaemia in rats. Gut 29: 489-494.

37. Otamiri T. Tagesson C. (1989) Ginkgo biloba extract prevents mucosal damage associated with small intestinal ischaemia. Scand. J. Gastroenterol. 29: 489-494.

38. Anderson JM, Van Itallie CM. (1995) Tight junctions and the molecular basis for regulation of paracellular permeability. Am. J. Physiol. 269(4 Pt 1): G467-G475.

39. Citi S. (1993) The molecular organization of tight junctions. J. Cell. Biol. 121: 485-489.

40. Denker BM, Nigam SK. (1998) Molecular structure and assembly of the tight junction. Am. $J$. Physiol. 274(1 Pt 2): F1-F9.

41. Saitou M, Fujimoto K, Doi Y, et al. (1998) Occludin-deficient embryonic stem cells can differentiate into polarized epithelial cells bearing tight junctions. J. Cell. Biol. 141: 397-408.

42. Balda MS, Whitney JA, Flores C, Gonzalez S, Cereijido M, Matter K. (1996) Functional dissociation of paracellular permeability and transepithelial electrical resistance and disruption of the apical-basolateral intramembrane diffusion barrier by expression of a mutant tight junction membrane protein. J. Cell. Biol. 134: 1031-1049.

43. Furuse M, Fujita K, Hiiragi T, Fujimoto K, Tsukita S. (1998) Claudin-1 and -2: novel integral membrane proteins localizing at tight junctions with no sequence similarity to occludin. $J$. Cell. Biol. 141: 1539-1550.

44. Tsukita S, Furuse M. (1999) Occludin and claudins in tight-junction strands: leading or supporting players? Trends Cell. Biol. 7: 268-273.

45. Youn YK, Lalonde C, Demling R. (1991) Use of antioxidant therapy in shock and trauma. Circ. Shock 35: 245-249.
46. Petrone WF, English DK, Wong K, McCord JM. (1980) Free radicals and inflammation: superoxide-dependent activation of a neutrophil chemotactic factor in plasma. Proc. Natl. Acad. Sci. USA 77: 1159-1165.

47. Miller FN, Sims DE. (1986) Contractile elements in the regulation of macromolecular permeability. Fed. Proc. 45: 84-88.

48. Schillier HJ, Reilly PM, Bulkley GB. (1993) Antioxidant terapy. Crit. Care Med. 21: 92-102.

49. Salvemini D, Wang ZQ, Zweier JL, et al. (1999) A nonpeptidyl mimic of superoxide dismutase with therapeutic activity in rats. Science 286: 304306.

50. Cuzzocrea S, Tan DX, Costantino G, Mazzon E, Caputi AP, Reiter RJ. (1999) The protective role of endogenous melatonin in carrageenaninduced pleurisy in the rat. FASEB J. 13: 19301938.

51. Cuzzocrea S, Costantino G, Mazzon E, De Sarro A, Caputi AP. (1999) Beneficial effects of Mn(III) tetrakis (4-benzoic acid) porphyrin (MnTBAP), a superoxide dismutase mimetic, in zymosan-induced shock. Br. J. Pharmacol. 128: 1241-1251.

52. Szabó C, Lim LHK, Cuzzocrea S, et al. (1997) Inhibition of poly (ADP-ribose) synthetase exerts anti-inflammatory effects and inhibits neutrophil recruitment. J. Exp. Med. 186: 1041-1049.

53. Szabó C, Viràg L, Cuzzocrea S, et al. (1998) Protection against peroxynitrite-induced fibroblast injury and arthritis development by inhibition of poly (ADP-Ribose) synthetase. Proc. Natl. Acad. Sci. USA 95: 3867-3872.

54. Szabo C, Cuzzocrea S, Zingarelli B, O'Connor M, Salzman AL. (1997). Endothelial dysfunction in a rat model of endotoxic shock. Importance of the activation of poly (ADP-ribose) synthetase by peroxynitrite. J. Clin. Invest. 100: 723-735

55. Goldblum SE, Ding $\mathrm{X}$, Campbell-Washington, J. (1993) NF- $\alpha$ induces endothelial cell F-actin depolymerization, new actin synthesis, and barrier dysfunction. Am. J. Physiol. 264: C894-905.

56. Katusic Z. (1996) Superoxide anion and endothelial regulation of arterial tone. Free. Rad. Biol. Med. 20: 443-448.

57. Darley-Usmar V, Halliwell B. (1996) Blood radicals. Reactive nitrogen species, reactive oxigen species, transition metal ions, and the vascular system. Pharmaceut. Res. 13: 649-662.

58. White CR, Brock TA, Chang LY, et al. (1994) Superoxide and peroxynitrite in atherosclerosis. Proc. Natl. Acad. Sci. USA 9: 1044-1048.

59. Xia Y, Dawson VL, Dawson TM, Snyder SH, Zweier JL. (1996) Nitric oxide synthase generates superoxide and nitric oxide in argininedepleted cells leading to peroxynitrite-mediated cellular injury. Proc. Natl. Acad. Sci. USA 93: 67706774. 